\title{
Left Ventricular Systolic and Diastolic Dysfunction after Infusion of Tumor Necrosis Factor- $\alpha$ in Conscious Dogs
}

\author{
Francis D. Pagani, Lauren S. Baker, Charles Hsi, Mark Knox, Mitchell P. Fink, and Marc S. Visnert \\ University of Massachusetts Medical Center, Department of Surgery, Worcester, Massachusetts 01655
}

\begin{abstract}
We used a load-insensitive index of systolic left ventricular (LV) function and an analysis of diastolic pressure-dimension relationships to test the hypothesis that recombinant human (rh) tumor necrosis factor- $\alpha$ (TNF $\alpha$ ) impairs $L V$ function in dogs. Animals were studied 7-10 d after aseptic implantation of instrumentation to monitor cardiac output, external anteriorposterior $\mathrm{LV}$ diameter, and $\mathrm{LV}$ and pleural pressures. Data were analyzed from seven dogs that received active rhTNF $\alpha$ $(100 \mu \mathrm{g} / \mathrm{kg}$ over $60 \mathrm{~min})$ and from five dogs that received heatinactivated rhTNF $\alpha$. At $24 \mathrm{~h}$ after infusion of active rhTNF $\alpha$, the slope of the $L V$ end-diastolic dimension-stroke work relationship decreased significantly, indicating a decrement in $\mathrm{LV}$ systolic contractility. Simultaneously, LV unstressed dimension increased significantly, suggesting diastolic myocardial creep. The end-diastolic relationship between $\mathrm{LV}$ transmural pressure and normalized LV dimension (strain) was markedly displaced to the left, suggesting increased diastolic elastic stiffness. Despite these changes in $\mathrm{LV}$ performance, cardiac index was maintained by tachycardia. The abnormalities in $L V$ function were resolved by $72 \mathrm{~h}$. We conclude that rhTNF $\alpha$ reversibly impairs $\mathrm{LV}$ systolic and diastolic function in unanesthetized dogs. Because dysfunction occurs $>6 \mathrm{~h}$ after the infusion of rhTNF $\alpha$ and persists for $24-48 \mathrm{~h}$, the mechanism underlying this phenomenon may involve secondary mediators or a change in myocardial gene expression. (J. Clin. Invest. 1992. 90:389398.) Key words: cytokine - myocardial contractility • myocardial blood flow $\bullet$ myocardial creep $\bullet$ myocardial stiffness
\end{abstract}

\section{Introduction}

Recent clinical and experimental studies strongly support the hypothesis that tumor necrosis factor- $\alpha(\mathrm{TNF} \alpha)^{1}$ is a mediator of organ dysfunction and shock induced by sepsis and endotox-

\section{†Deceased. \\ Address reprint requests to Dr. Pagani, Department of Surgery, Georgetown University Medical Center, 3800 Reservoir Road, NW, Washington, DC 20007-2197. \\ Received for publication 17 June 1991 and in revised form 21 Febru- ary 1992.}

1. Abbreviations used in this paper: BEL, ventricular dimension at beginning ejection; $C_{\mathrm{M}}$, tissue microsphere count; $C_{\mathrm{R}}$, reference microsphere count; $\epsilon$, Lagrangian strain; EDL, ventricular dimension at end diastole; EEL, ventricular dimension at end ejection; \%ES, fractional ejection shortening of left ventricular minor axis diameter; $L$, ventricular minor axis dimension; $L_{0}$, unstressed ventricular dimension; $L_{\mathrm{w}}$, $x$-intercept of the preload recruitable stroke-work relationship; LV, left

J. Clin. Invest.

(C) The American Society for Clinical Investigation, Inc. $0021-9738 / 92 / 08 / 0389 / 10 \quad \$ 2.00$

Volume 90, August 1992, 389-398 emia. Elevated plasma levels of TNF $\alpha$ are present in patients with a variety of infectious diseases (1), and plasma levels of TNF $\alpha$ correlate with morbidity and mortality due to meningicoccal meningitis (2). Administration of lipopolysaccharide (LPS) to humans (3) or animals $(4,5)$, and infusion of live bacteria in animals $(6,7)$ increases plasma levels of TNF $\alpha$. Administration of TNF $\alpha$ to humans $(8,9)$, mice $(10,11)$, rats (12-16), rabbits (17), dogs (18-20), and sheep $(21,22)$ elicits manifestations of sepsis and septic shock, including fever, hypotension, acidosis, leukopenia, histopathological evidence of organ injury, and death. In experimental animals, survival is improved when monoclonal (23) or polyclonal (24) antibodies against TNF $\alpha$ are administered before challenge with live Escherichia coli or LPS.

Studies in patients (25-28) and experimental animals (2932 ) indicate that alterations in myocardial performance are characteristic of sepsis and septic shock. Both left ventricular (LV) systolic dysfunction (depressed ejection fraction) and diastolic dysfunction (decreased chamber compliance) have been documented. Recent data suggest that TNF $\alpha$ is one of the mediators of sepsis-induced cardiac dysfunction. Recombinant human (rh) TNF $\alpha$ induces myocardial depression in dogs (19) and guinea pigs (S. O. Heard, M. W. Perkins, and M. P. Fink, personal communication ), and suppresses the positive inotropic effect of isoproteronol in cultured murine fetal heart cells (34).

The purpose of the present study was to rigorously test the hypothesis that $\operatorname{rhTNF} \alpha$ impairs LV systolic and diastolic function in chronically instrumented conscious dogs. Alterations in systolic LV function were assessed by analyzing changes in the preload recruitable stroke-work relationship. This relationship is a load-insensitive index of systolic myocardial function that relates increases in LV stroke work to increases in preload (end-diastolic volume or dimension) (35). Changes in the diastolic properties of the left ventricle were assessed by analyzing diastolic transmural pressure-dimension and transmural pressure-strain relationships. A preliminary report of these data has been published (36).

\section{Methods}

Surgical preparation. 22 adult mongrel dogs ( $20-33 \mathrm{~kg})$ were anesthetized with thiopental sodium ( $25 \mathrm{mg} / \mathrm{kg}$; Abbott Laboratories, North Chicago, IL) and maintained on $1 \%$ halothane (Halocarbon Laboratories, Inc., North Augusta, SC) and pancuronium bromide (0.05 mg/

ventricular; $M_{\mathrm{Sw}}$, slope of the preload recruitable stroke-work relationship; $P_{\mathrm{A}}$, arterial pressure; $P_{\mathrm{LV}}$, left ventricular intracavitary pressure; $P_{\mathrm{PL}}$, intrapleural pressure; $P_{\mathrm{RA}}$, right atrial pressure; $P_{\mathrm{TM}}$, left ventricular transmural pressure; $\dot{Q}$, cardiac output indexed to body weight; $\dot{Q}_{M}$, myocardial blood flow; $\dot{Q}_{R}$, reference blood flow; rhTNF $\alpha$, recombinant human tumor necrosis factor- $\alpha$; SVRI, systemic vascular resistance index; SW, stroke work; TNF $\alpha$, tumor necrosis factor- $\alpha$. 
kg; Quad Pharmaceutical, Inc., Indianapolis, IN). All animals received intravenous cefazolin ( $500 \mathrm{mg}$; Eli Lilly \& Co., Indianapolis, IN ) preoperatively. A left thoracotomy was performed through the fifth intercostal space, and the pericardium was opened and suspended to expose the heart. A pair of ultrasonic dimension transducers (Physiologic Monitoring Systems Group, Durham, NC) were implanted on the LV epicardium adjacent to the anterior and posterior descending coronary arteries to measure the external LV anterior-posterior minor axis diameter (Fig. 1). A pulsed transit time ultrasonic flow probe (model 14348, 12 or $14 \mathrm{~mm}$ o.d.; Transonic Systems Inc., Ithaca, NY) was implanted around the pulmonary artery to monitor cardiac output. A silicone rubber catheter (2.6 mm i.d., $4.9 \mathrm{~mm}$ o.d.; Dow Corning, Midland, MI) was implanted in the base of the left atrium for injection of microspheres and passage of a catheter-tipped micromanometer to measure LV intracavitary pressure $\left(P_{\mathrm{LV}}\right)$ during subsequent studies. Another silicone rubber catheter was implanted in the right atrial appendage for measuring right atrial pressure $\left(P_{\mathrm{RA}}\right)$ and sampling venous blood. A third silicone rubber catheter, closed at its distal end by a compliant silicone rubber balloon (1/100 in thickness), was positioned in the chest at the level of the aortic arch for subsequent passage of a micromanometer to measure intrapleural pressure $\left(P_{\mathrm{PL}}\right)$. Inflatable silicone rubber occluders (Isis Inc., Minneapolis, $M N$ ) were placed around the venae cavae for performing transient vena caval occlusions. The azygous vein was ligated to insure cessation of venous inflow during vena caval occlusions. A fluid-filled polyvinyl chloride catheter was inserted through the left internal mammary artery into the aortic arch to measure arterial pressure $\left(P_{\mathrm{A}}\right)$ and to collect arterial blood samples. The electrical leads, catheters, and occluders were all exteriorized dorsal to the thoracotomy incision. A 20 French thoracostomy tube was implanted for postoperative evacuation of fluid and air. The pericardium was left open, and the chest was closed. Postoperatively, all animals received dihydrostreptomycin $(0.05 \mathrm{~g}$ i.m. $)$ and procaine penicillin (400,000 U i.m.) daily for $6 \mathrm{~d}$ (Pfizer Inc., New York). Thoracostomy tubes were removed on the third to fifth postoperative day. The animals were monitored according to the guidelines of the Committee on Animal Research of the University of Massachusetts Medical Center and those prepared by the Committee on Care and Use of Laboratory Animals of the Institute of Laboratory Animal Resources, National Council (DHEW Publication No. [NIH] 85-23, revised 1985).

Instrumentation and data acquisition. Animals were allowed to recover for 7-10 d before being studied. Data were collected with the animals awake and unsedated. $P_{\mathrm{LV}}$ and $P_{\mathrm{PL}}$ were measured using high fidelity micromanometers (model MPC 500; Millar, Inc., Houston, TX) inserted through the left atrial and pleural catheters, respectively. The micromanometers were zeroed and balanced to atmospheric pressure at $38^{\circ} \mathrm{C}$. Pressures in the ascending aorta and right atrium were measured using external transducers (model 800; Bentley Trantec, Elk Grove, IL) connected to the fluid-filled catheters that had been implanted in the aorta and right atrium, respectively. Cardiac rhythm was monitored from lead II of the electrocardiogram.

The ultrasonic dimension transducers were coupled to a sonomicrometer (James W. Davis, Inc., Durham, NC) with a minimal resolution of $0.08 \mathrm{~mm}$, and maximal electronic drift of $0.05 \mathrm{~mm} / \mathrm{h}$. The ultrasonic flow probe on the pulmonary artery was coupled to a pulsed transit time flowmeter (Transonic Systems, Inc., Ithaca, NY). Analog signals representing pressures and flow were passed through a series of preamplifiers (Litton Medical Electronics, Inc., Elk Grove, IL) and, together with the signals representing dimension and flow were processed by medium gain amplifiers (James $W$. Davis, Inc.). The signals were recorded on an eight-channel FM tape recorder (AP Vetter Co., Rebersburg, PA) and simultaneously digitized at a sweep rate of 200 $\mathrm{Hz}$ per channel using an analog-to-digital converter (model 1012; ADAC, Woburn, MA) interfaced with a PDP $11 / 73$ computer (Digital Equipment Corp., Maynard, MA).

Experimental Protocol. After the surgical implantation of instrumentation, rectal temperature $(T)$ and body weight were monitored daily. At the time of each study, recordings of heart rate (HR), $P_{\mathrm{A}}, P_{\mathrm{RA}}$, $P_{\mathrm{LV}}, P_{\mathrm{PL}}, \mathrm{LV}$ dimension, and cardiac output were acquired. Arterial blood samples were obtained for determination of $\mathrm{pH}, \mathrm{PCO}_{2}$, and $\mathrm{PO}_{2}$ (System 1302 blood gas analyzer; Instrumentation Laboratories, Inc., Lexington, MA), and lactate concentration (model 23L lactate analyzer, Yellow Springs Instrument Co., Yellow Springs, $\mathrm{OH}$ ). Venous blood samples were obtained for determination of plasma concentration of the stable prostacyclin metabolite, 6-keto-PGF ${ }_{1 \alpha}$ (37). Signals were then recorded during transient vena caval occlusions, performed over $30 \mathrm{~s}$ to bring peak systolic $P_{\mathrm{LV}}$ to $30 \mathrm{mmHg}$.

Baseline data were acquired on the day before rhTNF $\alpha$ administration (day -1 ) and just before administration (day 0). Animals then received either $100 \mu \mathrm{g} / \mathrm{kg}$ of recombinant human rhTNF $\alpha$ or $100 \mu \mathrm{g} /$ $\mathrm{kg}$ of heat-inactivated $\operatorname{rhTNF} \alpha$ (denatured by boiling for $30 \mathrm{~min}$ ). Recombinant human TNF $\alpha$ (lot EB6011) was supplied by Knoll Pharmaceuticals Inc., Whippany, NJ. Specific activity was $1 \times 10^{7} \mathrm{U} / \mathrm{mg}$
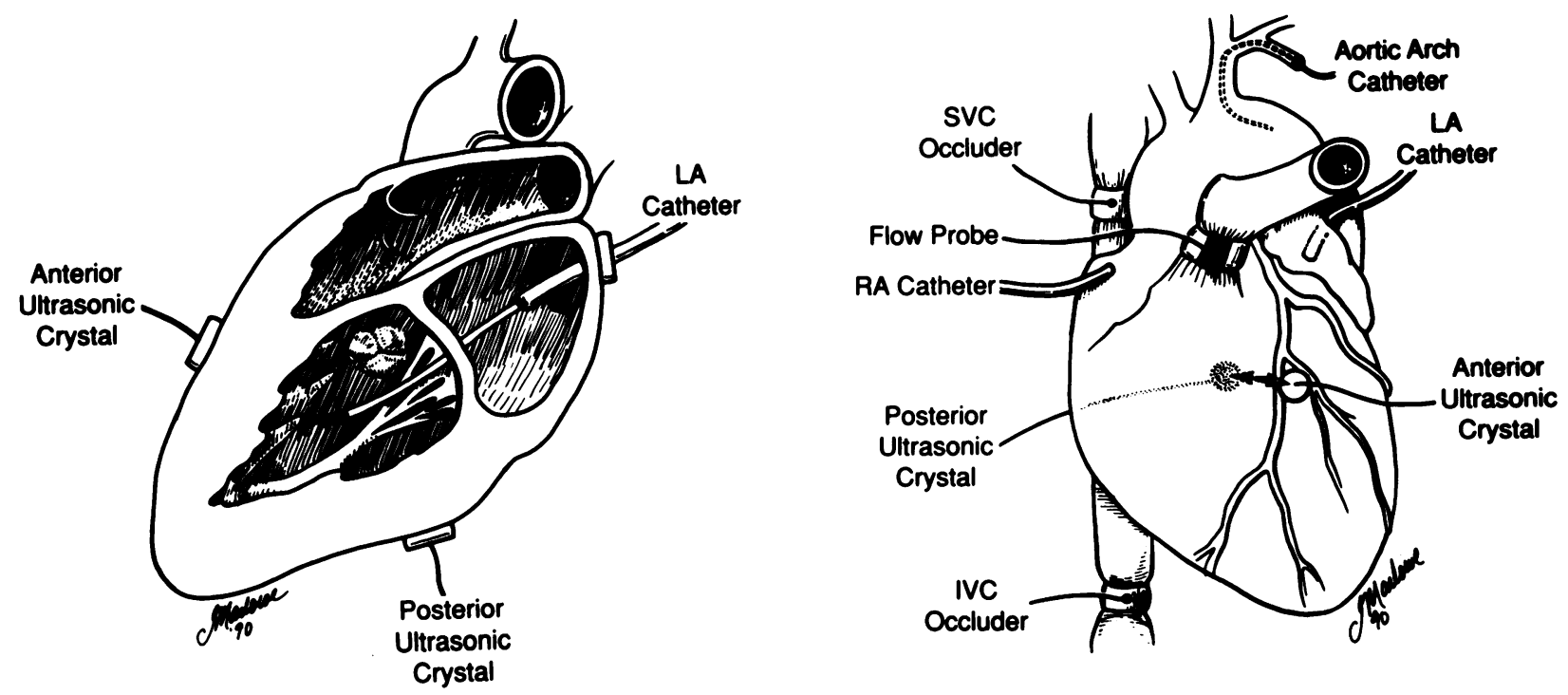

Figure 1. Implantation of instrumentation to monitor cardiac output (pulmonary artery flow probe), external LV anterior-posterior dimension (ultrasonic crystals), aortic and right atrial pressures (fluid-filled catheters). LV pressure was measured with a micromanometer introduced through an implanted left atrial catheter. Inflatable vena caval occluders permitted the adjustment of LV loading during experiments. 
protein, and the LPS content was $<0.5 \mathrm{ng} / \mathrm{mg}$ protein (manufacturer's data). Individual doses of active rhTNF $\alpha$ or heat-inactivated rhTNF $\alpha$ were reconstituted in $20 \mathrm{ml}$ of saline and administered over 1 h. The administration tubing and syringes were treated with $3 \mathrm{ml}$ of dog plasma before each infusion. Animals received infusions of normal saline before each study to bring end-diastolic $P_{\mathrm{LV}}$ to its baseline level. After administration of active or heat-inactivated rhTNF $\alpha$, data were obtained at 3 and $6 \mathrm{~h}$, and at 1,2,3,5, and $7 \mathrm{~d}$ (data from days 3 and 5 are not presented). Myocardial blood flows were determined by injecting color-coded microspheres through the left atrial catheter and sampling blood from the aortic catheter on days 0,2 , and 7 . Aerobic and anaerobic blood cultures were obtained from a peripheral vein on days 0,2 , and 7 .

At the conclusion of the experiments, the animals were euthanized, and the positions of the ultrasonic dimension transducers were confirmed at autopsy. For the purpose of determining myocardial blood flow, the left ventricle was sectioned into four concentric rings of approximately equal thickness in the plane of the minor axis. The middle two rings were divided into three regions representing the interventricular septum, anterior free wall, and posterolateral free wall. These samples were dissected into epicardial, midmyocardial, and endocardial sections. The epicardial and endocardial thirds (weighing 2-3 g) were then chemically digested, and the number of spheres was determined in each sample (38).

Data analysis. The first derivative of $P_{\mathrm{LV}}(\mathrm{d} P / \mathrm{d} t)$ was calculated as a running five-point orthogonal polynomial approximation from the digital pressure waveform. Diastolic and ejection phases of the cardiac cycle were defined using interactive software. The beginning of diastolic filling was defined as the first zero crossing of the $\mathrm{d} P / \mathrm{d} t$ waveform following peak negative $\mathrm{d} P / \mathrm{d} t$ (39). End diastole was defined as the upstroke of the $\mathbf{R}$ wave of the electrocardiogram (39). Beginning ejection was defined as the point $10 \mathrm{~ms}$ after peak positive $\mathrm{d} P / \mathrm{d} t(39)$. End ejection was defined as the point 20 ms before peak negative $\mathrm{d} P$ / $\mathrm{d} t(39,40)$. Only data from the mid- to end-expiratory phase of the respiratory cycle were considered for analysis to minimize respiratory variation in $P_{\mathrm{LV}}$ and $\mathrm{LV}$ dimension.

$\mathrm{LV}$ transmural pressure $\left(P_{\mathrm{TM}}\right)$ was calculated as the difference between $P_{\mathrm{LV}}$ and $P_{\mathrm{PL}}: P_{\mathrm{TM}}=P_{\mathrm{LV}}-P_{\mathrm{PL}}$.

An analogue of $\mathrm{LV}$ stroke work ( $\mathrm{SW}$ ) was calculated for individual cardiac cycles as the integral of $P_{\mathrm{TM}}$ versus $\mathrm{LV}$ anterior-posterior minor axis dimension. Fractional global ejection shortening (\%ES) was defined as the change in LV minor axis dimension during the ejection phase of the cardiac cycle normalized to end-diastolic dimension: \%ES $=(B E L-E E L) / E D L$ where BEL, EEL, and EDL are beginning ejection, end ejection, and end-diastolic dimension, respectively.

For the purpose of characterizing systolic LV contractility, transient vena caval occlusions were performed to permit the construction of the relationship between $S W$ and $L V$ end-diastolic dimension over a wide range of loading. Data were fit by linear least squares regression to the equation: $\mathrm{SW}=M_{\mathrm{Sw}}\left(\mathrm{EDL}-L_{\mathrm{w}}\right)$, where $M_{\mathrm{Sw}}$ and $L_{\mathrm{w}}$ are the derived slope and $x$-intercept, respectively. Only that portion of the vena caval occlusion in which $\mathrm{HR}$ changed by $<10 \%$ was considered for analysis.

For the purpose of assessing the passive diastolic compliance of the LV chamber, measured anterior-posterior minor axis dimension was normalized to a Lagrangian strain ( $\epsilon$; fractional extension from unstressed dimension $): \epsilon=\left(L-L_{0}\right) / L_{0}$, where $\epsilon$ is the Lagrangian strain of dimension $L$, and $L_{0}$ is the unstressed diastolic dimension, determined at maximal vena caval occlusion, when $P_{\mathrm{TM}}$ was equal to 0 $\mathrm{mmHg}$.

Diastolic compliance of the left ventricle was determined by analyzing the relationship between end-diastolic $P_{\mathrm{TM}}$ and strain. These data were fit by nonlinear least squares regression to the equation: $P_{\mathrm{TM}}=\alpha$ $\left(e^{\beta \epsilon}-1\right)$, where $\alpha$ and $\beta$ are elastic constants determined from the curve fit (41). To compare the pressure-strain relationships of the two experimental groups, the derived $\alpha$ and $\beta$ values were used to compute strains at $\mathrm{LV}$ transmural pressures of 5, 10, and 15 , and $20 \mathrm{mmHg}$. For each group, means and standard deviations of the values of strain at each pressure were then computed. For the purpose of illustration, exponential forms were also fit to the relationship between end-diastolic $P_{\mathrm{TM}}$ and end-diastolic raw dimension $(L)$, again using nonlinear least squares regression: $P_{\mathrm{TM}}=\alpha\left(e^{\beta \mathrm{L}}-e^{\beta \mathrm{L}_{0}}\right)$.

Determination of cardiac output and systemic vascular resistance: Cardiac output indexed to body weight $(\dot{Q})$ was computed by dividing the mean pulmonary artery flow measurement by body weight. Systemic vascular resistance index $(\mathrm{SVRI})$ was calculated as: $\mathrm{SVRI}=\left(P_{\mathrm{A}}\right.$ $\left.-P_{\mathrm{RA}}\right) / \dot{Q}$.

Assay for plasma levels of 6-keto-PGF $F_{1 \alpha}$. Venous blood samples were collected into iced-glass tubes containing $100 \mu \mathrm{g}$ of indomethacin and $10.5 \mathrm{mg}$ of EDTA. Samples were then centrifuged $(1,500 \mathrm{~g})$ at $4^{\circ} \mathrm{C}$ for $15 \mathrm{~min}$. The plasma was collected and stored in polypropylene tubes at $-70^{\circ} \mathrm{C}$ until assayed. Details of the radioimmunoassay for

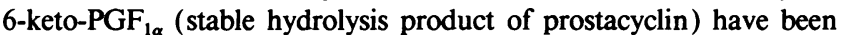
reported previously (37). The lower limit of sensitivity for the assay is $30 \mathrm{pg} / \mathrm{ml}$. All samples were run in a single assay to obviate interassay variability.

Determination of myocardial blood flow. Microspheres were agitated for $10 \mathrm{~min}$ before injection. 7-10 million spheres $(15 \mu \mathrm{m})$ were injected through the left atrial catheter and flushed with $10 \mathrm{ml}$ of normal saline. A reference arterial blood sample was obtained from the aortic arch at a withdrawal rate of $13.8 \mathrm{ml} / \mathrm{min}$ beginning $5 \mathrm{~s}$ before injection and continuing for $90 \mathrm{~s}$. Myocardial blood flow, indexed per gram of tissue $\left(\dot{Q}_{\mathrm{M}}\right)$, was calculated as: $\dot{Q}_{\mathrm{M}}=C_{\mathrm{M}} \cdot \dot{Q}_{\mathrm{R}} / C_{\mathrm{R}}$, where $C_{\mathrm{M}}$ is the microsphere count in the tissue sample, $C_{\mathrm{R}}$ is the number of spheres in the blood reference sample, and $\dot{Q}_{R}$ is the withdrawal rate of the reference sample.

Statistical analysis. Statistical analyses were performed using commercially available software (SAS Institute, Inc., Cary, NC). For the analyses of myocardial function, the calculated parameters from ten cardiac cycles were averaged. Two-way analysis of variance (ANOVA) with repeated measures was used to compare parameters to their baseline values (at $-24 \mathrm{~h}$ ) over time (within groups) and to compare timematched parameters between groups (42). When statistically significant differences were identified by ANOVA for group effects or grouptime interactions, Tukey's studentized range test for multiple comparisons was used to compare means at individual time points (43). When statistically significant differences within groups over time were observed by ANOVA, single degree of freedom $F$-tests were used to compare the means at each time with baseline. Bonferonni's correction was utilized to compensate for the increased risk of a type I error with multiple comparisons (44). The null hypothesis was rejected for $P$ $<0.05$. Data are presented throughout the tables as means $\pm 1 \mathrm{SD}$.

\section{Results}

Disposition of experimental animals (Table I). Of the 22 dogs that underwent implantation of the instrumentation, six were excluded because of technical failures or infectious complications. Of the 16 dogs entered into the study, 10 received active $\operatorname{rhTNF} \alpha$ and six received inactivated rhTNF $\alpha$. Data from 12 of these 16 animals were analyzed; seven that had received active rhTNF $\alpha$ and five controls. Four of the five dogs that died had positive blood cultures and were excluded from the final data analysis. One of the five deaths (active rhTNF $\alpha$ group) occurred at $72 \mathrm{~h}$, immediately after passage of the manometertipped catheter into the left ventricle. This death was attributed to an embolic event, and because blood cultures in this animal were negative at 0 and $48 \mathrm{~h}$, data collected before death were analyzed.

Metabolic and respiratory parameters (Table II). There were no significant differences between groups at baseline for these variables: temperature $\left(101.9 \pm 0.7\right.$ vs. $102.0 \pm 0.6^{\circ} \mathrm{F}$ for control and rhTNF $\alpha$ groups, respectively), arterial pH, $\mathrm{Po}_{2}$, $\mathrm{PCO}_{2}$, and bicarbonate. Controls had slightly higher blood lac- 
Table I. Disposition of Experimental Animals

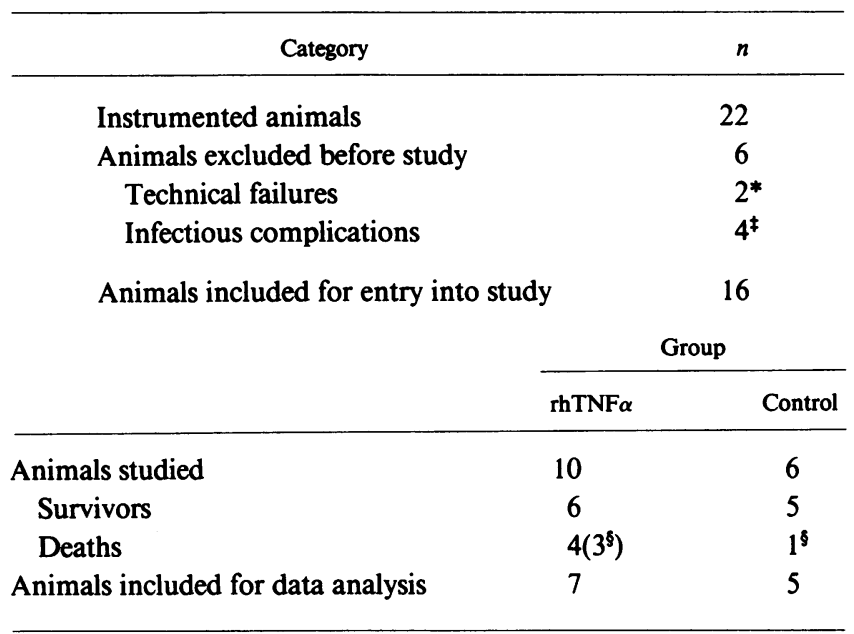

Deaths occurred at $6 \mathrm{~h}(2)$ and $48 \mathrm{~h}(1)$ in the active rhTNF $\alpha$ group and $6 \mathrm{~h}(1)$ in the controls. One death (72 h) in the active rhTNF $\alpha$ group had negative blood cultures and was included in the final data analysis. * Technical failures (instrumentation failure [2]). ${ }^{\ddagger}$ Infectious complications (pneumonia [2], empyema [1], unidentified source [1]). Animals excluded from the final data analysis because of positive blood cultures (identified organisms: Enterobacter cloacae [1]; Acinetobacter caloaceticus [1]; Staphylococcus aureus [1]; Propinibacteria [1]).

tate concentrations at baseline than did dogs in the $\operatorname{rhTNF} \alpha$ group.

Administration of heat-inactivated $\operatorname{rhTNF} \alpha$ was associated with minimal changes in temperature $(101.7 \pm 0.8,101.6 \pm 0.5$, 101.2 $\pm 0.6,101.3 \pm 0.9$, and $102.9 \pm 0.4^{\circ} \mathrm{F}$ at $3,6,24,48 \mathrm{~h}$, and 7 $\mathrm{d}$, respectively), arterial blood gases, and arterial concentrations of bicarbonate ion and lactate. Infusion of active rhTNF $\alpha$ elicited a marked febrile response at 3 and $6 \mathrm{~h}$ (104.8 \pm 1.1 and 103.2 $\pm 0.1^{\circ} \mathrm{F}$, respectively, $P<0.05$ as compared to baseline,

Table II. Effects of rhTNF $\alpha$ on Arterial pH, $\mathrm{PO}_{2}, \mathrm{PCO}_{2}$, Bicarbonate, and Lactate Concentration

\begin{tabular}{|c|c|c|c|c|c|}
\hline Time & pH & $\mathrm{PO}_{2}$ & $\mathrm{PCO}_{2}$ & Bicarbonate & Lactate \\
\hline$h$ & & \multicolumn{2}{|c|}{$\mathrm{mmHg}$} & \multicolumn{2}{|c|}{ meq/liter } \\
\hline \multicolumn{6}{|l|}{ Control } \\
\hline-24 & $7.42 \pm 0.02$ & $84 \pm 5$ & $37 \pm 2$ & $24 \pm 1$ & $1.1 \pm 0.2$ \\
\hline 0 & $7.44 \pm 0.03$ & $83 \pm 4$ & $36 \pm 2$ & $24 \pm 1$ & $1.0 \pm 0.3$ \\
\hline 3 & $7.40 \pm 0.02$ & $85 \pm 4$ & $37 \pm 2$ & $23 \pm 2$ & $0.7 \pm 0.2$ \\
\hline 6 & $7.40 \pm 0.03$ & $86 \pm 3$ & $37 \pm 3$ & $24 \pm 2$ & $0.6 \pm 0.2^{*}$ \\
\hline 24 & $7.42 \pm 0.01$ & $84 \pm 5$ & $36 \pm 3$ & $24 \pm 2$ & $0.7 \pm 0.2$ \\
\hline 48 & $7.41 \pm 0.02$ & $92 \pm 3^{*}$ & $35 \pm 2$ & $23 \pm 2$ & $1.0 \pm 0.2$ \\
\hline 168 & $7.43 \pm 0.03$ & $81 \pm 6$ & $36 \pm 3$ & $24 \pm 4$ & $1.2 \pm 0.6$ \\
\hline \multicolumn{6}{|c|}{$\operatorname{rhTNF} \alpha$} \\
\hline-24 & $7.41 \pm 0.03$ & $84 \pm 6$ & $36 \pm 2$ & $23 \pm 2$ & $0.7 \pm 0.3^{\ddagger}$ \\
\hline 0 & $7.42 \pm 0.02$ & $85 \pm 5$ & $35 \pm 2$ & $23 \pm 1$ & $0.7 \pm 0.1$ \\
\hline 3 & $7.40 \pm 0.04$ & $78 \pm 6^{* \neq}$ & $30 \pm 3^{* \neq}$ & $19 \pm 2^{* \pm}$ & $1.8 \pm 0.1^{*}$ \\
\hline 6 & $7.28 \pm 0.07^{* \pm}$ & $82 \pm 7$ & $29 \pm 3^{* \neq}$ & $14 \pm 3^{* \pm}$ & $2.6 \pm 1.3^{*}$ \\
\hline 24 & $7.31 \pm 0.03^{* \pm}$ & $83 \pm 7$ & $28 \pm 6^{* \neq}$ & $16 \pm 2^{* t}$ & $0.7 \pm 0.2$ \\
\hline 48 & $7.36 \pm 0.05^{* \neq}$ & $85 \pm 5^{\ddagger}$ & $31 \pm 6^{*}$ & $21 \pm 6$ & $0.5 \pm 0.1^{\ddagger}$ \\
\hline 168 & $7.43 \pm 0.02$ & $80 \pm 6$ & $34 \pm 6$ & $24 \pm 2$ & $0.6 \pm 0.2$ \\
\hline
\end{tabular}

${ }^{*} P<0.05$ as compared to baseline. ${ }^{\ddagger} P<0.05$ as compared to control.
$102.0 \pm 0.6^{\circ} \mathrm{F}$ and time-matched value in the control group). There were no significant differences in temperature at 24 and $48 \mathrm{~h}$, and $7 \mathrm{~d}(101.2 \pm 0.6,101.3 \pm 0.9$, and $102.9 \pm 0.4$, respectively). Metabolic acidosis was present 6 and $24 \mathrm{~h}$ after infusion of the active cytokine. Arterial bicarbonate concentration was decreased at 3,6 , and $24 \mathrm{~h}$; circulating lactate concentrations were increased at 3 and $6 \mathrm{~h}$.

Compared to controls, arterial $\mathrm{Po}_{2}$ was transiently lower in the rhTNF $\alpha$ group at $3 \mathrm{~h}$. In the active rhTNF $\alpha$ group, arterial $\mathrm{PCO}_{2}$ was decreased at $3,6,24$, and $48 \mathrm{~h}$, but recovered to baseline at $72 \mathrm{~h}$.

Hemodynamic variables (Table III). At baseline, hemodynamic variables were comparable in the two groups. Administration of heat-inactivated $\operatorname{rhTNF} \alpha$ did not affect HR, peak systolic $P_{\mathrm{TM}}$, end-diastolic $P_{\mathrm{TM}}, \bar{P}_{\mathrm{A}}, \mathrm{d} P / \mathrm{d} t, \dot{Q}$, or SVRI. In contrast, infusion of active $\operatorname{rhTNF} \alpha$ significantly increased $\mathrm{HR}$, peak systolic $P_{\mathrm{TM}}$, and $\mathrm{d} P / \mathrm{d} t$ at $3 \mathrm{~h} .6 \mathrm{~h}$ after the administration of active rhTNF $\alpha$, HR remained elevated, but peak systolic $P_{\mathrm{TM}}$ and $\mathrm{d} P / \mathrm{d} t$ recovered to baseline values. At $24 \mathrm{~h}$, HR was elevated, whereas peak systolic $P_{\mathrm{TM}}, \mathrm{d} P / \mathrm{d} t, \bar{P}_{\mathrm{A}}$, and SVRI were significantly decreased from baseline. By $48 \mathrm{~h}, \mathrm{HR}$, peak systolic $P_{\mathrm{TM}}, \bar{P}_{\mathrm{A}}$, and SVRI were all similar to baseline values, although $\mathrm{d} P / \mathrm{d} t$ was still decreased compared to baseline and compared to the time-matched value in the control group. Except for significantly lower $\mathrm{d} P / \mathrm{d} t$ in the active rhTNF $\alpha$ group at $72 \mathrm{~h}(2,436 \pm 414$ vs. $3,201 \pm 318$ for rhTNF $\alpha$ and control groups, respectively), there were no further significant differences in hemodynamic variables between the two groups.

In order to maintain end-diastolic $P_{\mathrm{Lv}}$ at its baseline value during the course of each study, animals receiving active rhTNF $\alpha$ required resuscitation with a larger $(P<0.05)$ volume of normal saline as compared to baseline and time-matched control values at 3,6 , and $24 \mathrm{~h}(17 \pm 10$ vs. $18 \pm 18,2 \pm 3$ vs. $34 \pm 14,2 \pm 4$ vs. $39 \pm 20,4 \pm 6$ vs. $65 \pm 27,12 \pm 12$ vs. $24 \pm 22$, and $9 \pm 11$ vs. $17 \pm 16 \mathrm{ml} / \mathrm{kg}$ for control and rhTNF $\alpha$ groups at $-24,3,6,24,48 \mathrm{~h}$, and $7 \mathrm{~d}$, respectively.

Left ventricular function (Table IV). There were no significant differences between the two groups in the baseline indices of systolic myocardial contractile function ( $\mathrm{SW}, \% \mathrm{ES}$, or slope and intercept of the preload recruitable stroke-work relationship). LV stroke work, \%ES, and the slope and $x$-intercept of the preload recruitable stroke-work relationship were stable in animals infused with heat-inactivated rhTNF $\alpha$ (Figs. 2 and 3 ).

At 3 and $6 \mathrm{~h}$ after the administration of active rhTNF $\alpha$, there was no evidence of systolic myocardial dysfunction as assessed by analysis of SW and the slope and intercept of the preload recruitable stroke work relationship. Fractional ejection shortening was significantly smaller than in the controls at $3,6,24,48$, and $72 \mathrm{~h}$.

At $24 \mathrm{~h}$, both SW and \%ES were decreased significantly from baseline. These changes were accompanied by a decrease in the slope and a rightward shift (increase in $x$-intercept) of the preload recruitable stroke-work relationship, so that at any given LV end-diastolic dimension, LV stroke work was significantly decreased (Fig. 3). By 48 h, SW and the slope and intercept of the preload recruitable stroke-work relationship were not significantly different from baseline, although the $x$-intercept remained significantly different from the controls until $72 \mathrm{~h}$.

The diastolic relationships between $\mathrm{LV}$ end-diastolic $\boldsymbol{P}_{\mathrm{TM}}$ and either LV end-diastolic dimension (Fig. 4) or normalized 
Table III. Effects of rhTNF $\alpha$ on Hemodynamic Indexes

\begin{tabular}{|c|c|c|c|c|c|c|c|}
\hline Time & Heart rate & $\begin{array}{l}\text { Peak systolic LV } \\
\text { transmural pressure }\end{array}$ & $\begin{array}{l}\text { End-diastolic LV } \\
\text { transmural pressure }\end{array}$ & $\begin{array}{l}\text { Mean arterial } \\
\text { pressure }\end{array}$ & $d P / d t$ & Cardiac index & $\begin{array}{l}\text { Systemic vascular } \\
\text { resistance index }\end{array}$ \\
\hline$h$ & beats $\cdot \mathrm{min}^{-1}$ & & $m m H g$ & & $m m H g \cdot s^{-1}$ & liters $\cdot \min ^{-1} \cdot \mathrm{kg}^{-1}$ & $\mathrm{mmHg} \cdot \min \cdot \mathrm{kg} \cdot$ liter $^{-1}$ \\
\hline \multicolumn{8}{|l|}{ Control } \\
\hline-24 & $102 \pm 13$ & $126 \pm 4$ & $13.5 \pm 1.2$ & $111 \pm 4$ & $3,112 \pm 473$ & $0.14 \pm 0.02$ & $868 \pm 284$ \\
\hline 0 & $96 \pm 15$ & $128 \pm 9$ & $14.1 \pm 2.5$ & $110 \pm 8$ & $3,011 \pm 403$ & $0.13 \pm 0.02$ & $858 \pm 277$ \\
\hline 3 & $95 \pm 18$ & $127 \pm 9$ & $13.4 \pm 3.2$ & $111 \pm 6$ & $3,126 \pm 433$ & $0.13 \pm 0.02$ & $837 \pm 139$ \\
\hline 6 & $95 \pm 16$ & $123 \pm 6$ & $11.2 \pm 2.7$ & $108 \pm 4$ & $3,227 \pm 367$ & $0.13 \pm 0.03$ & $819 \pm 228$ \\
\hline 24 & $92 \pm 18$ & $126 \pm 5$ & $12.1 \pm 3.1$ & $110 \pm 3$ & $3,037 \pm 366$ & $0.12 \pm 0.02$ & $946 \pm 252$ \\
\hline 48 & $96 \pm 14$ & $124 \pm 8$ & $11.2 \pm 1.7$ & $109 \pm 7$ & $3,094 \pm 375$ & $0.14 \pm 0.04$ & $842 \pm 382$ \\
\hline 168 & $95 \pm 23$ & $132 \pm 4$ & $13.9 \pm 3.3$ & $117 \pm 4$ & $3,275 \pm 124$ & $0.13 \pm 0.03$ & $947 \pm 294$ \\
\hline \multicolumn{8}{|l|}{$\operatorname{rhTNF} \alpha$} \\
\hline-24 & $100 \pm 16$ & $133 \pm 8$ & $13.5 \pm 5.5$ & $115 \pm 7$ & $2,803 \pm 290$ & $0.11 \pm 0.01$ & $934 \pm 58$ \\
\hline 0 & $99 \pm 17$ & $136 \pm 10$ & $13.6 \pm 5.2$ & $114 \pm 11$ & $2,971 \pm 319$ & $0.12 \pm 0.01$ & $920 \pm 119$ \\
\hline 3 & $117 \pm 25^{*}$ & $145 \pm 9^{* *}$ & $9.3 \pm 4.9$ & $117 \pm 9$ & $3,280 \pm 715^{*}$ & $0.13 \pm 0.03$ & $969 \pm 312$ \\
\hline 6 & $121 \pm 15^{* \pm}$ & $132 \pm 8$ & $10.8 \pm 5.1$ & $108 \pm 13$ & $2,984 \pm 597$ & $0.13 \pm 0.02$ & $879 \pm 122$ \\
\hline 24 & $133 \pm 19^{* \pm}$ & $112 \pm 16^{*}$ & $14.6 \pm 4.6$ & $95 \pm 17^{*}$ & $1,789 \pm 454^{* \neq}$ & $0.12 \pm 0.01$ & $674 \pm 124^{*}$ \\
\hline 48 & $110 \pm 15$ & $127 \pm 8$ & $16.1 \pm 5.7$ & $113 \pm 7$ & $1,972 \pm 310^{* \neq}$ & $0.10 \pm 0.01$ & $1,091 \pm 190$ \\
\hline 168 & $105 \pm 7$ & $139 \pm 6$ & $13.4 \pm 4.6$ & $116 \pm 6$ & $3,165 \pm 282$ & $0.14 \pm 0.03$ & $853 \pm 222$ \\
\hline
\end{tabular}

${ }^{*} P<0.05$ as compared to baseline. ${ }^{\ddagger} P<0.05$ as compared to control group.

LV dimension (strain) (Figs. 5 and 6) were not significantly different at baseline between the control and active $\operatorname{rhTNF} \alpha$ groups. Administration of heat-inactivated rhTNF $\alpha$ had no effect on these relationships (Fig. 4) or on unstressed LV dimension (Table IV).

Administration of active rhTNF $\alpha$ elicited significant changes in the diastolic relationships of the left ventricle that were initially manifested $24 \mathrm{~h}$ after infusion of the cytokine. These changes were characterized by a rightward shift of the LV end-diastolic $P_{\mathrm{TM}}$-dimension relationship (Fig. 4) and an increase in $L_{0}$ (Table IV). On the basis of the increase in $L_{0}$, there was a significant leftward shift in the end-diastolic $P_{\mathrm{TM}}-$ strain relationship (Figs. 5 and 6 ), with significant differences from the controls evident at 24 and $48 \mathrm{~h}$. The leftward shift of the end-diastolic $P_{\mathrm{TM}}$-strain relationship is consistent with a decrease in LV chamber compliance. By $72 \mathrm{~h}$, the end-diastolic $P_{\text {TM }}$-strain relationship returned to baseline (Figs. 5 and 6).

Myocardial blood flow (Table V). There were no significant differences in baseline subepicardial or subendocardial $\dot{Q}_{M}$ between control and active rhTNF $\alpha$ groups. After the ad-

Table IV. Effects of rhTNF $\alpha$ on Fractional Ejection Shortening, LV Stroke Work, Intercept of the Preload Recruitable StrokeWork Relationship, $L_{0}$, Slope of the Preload Recruitable Stroke-Work Relationship, and LV End-Diastolic Dimension

\begin{tabular}{|c|c|c|c|c|c|c|}
\hline Time & $\begin{array}{c}\text { LV } \\
\text { stroke work }\end{array}$ & $\begin{array}{c}\text { LV } \\
\text { fractional ejection } \\
\text { shortening }\end{array}$ & $\begin{array}{l}\text { Slope of the preload } \\
\text { recruitable stroke-work } \\
\text { relationship }\end{array}$ & $\begin{array}{l}\text { Intercept of the preload } \\
\text { recruitable stroke-work } \\
\text { relationship }\end{array}$ & $\begin{array}{l}\text { Unstressed } \\
L V \\
\text { dimension }\end{array}$ & $\begin{array}{c}\text { LV } \\
\text { end-diastolic } \\
\text { dimension }\end{array}$ \\
\hline$h$ & $\mathrm{ergs} \cdot \mathrm{cm}^{-2}$ & $\%$ & $\mathrm{ergs} \cdot \mathrm{cm}^{-2} \cdot \mathrm{mm}^{-1}$ & & $m m$ & \\
\hline \multicolumn{7}{|l|}{ Control } \\
\hline-24 & $77,230 \pm 15,110$ & $9.1 \pm 1.0$ & $8,698 \pm 2,341$ & $44.3 \pm 2.2$ & $42.6 \pm 2.1$ & $54.7 \pm 4.0$ \\
\hline 0 & $75,415 \pm 12,143$ & $8.9 \pm 0.7$ & $8,141 \pm 1,894$ & $44.2 \pm 2.1$ & $42.8 \pm 2.1$ & $53.9 \pm 3.5$ \\
\hline 3 & $75,665 \pm 11,864$ & $8.9 \pm 0.9$ & $7,861 \pm 1,500$ & $43.3 \pm 2.8$ & $42.0 \pm 2.6$ & $53.8 \pm 3.7$ \\
\hline 6 & $76,753 \pm 14,000$ & $9.2 \pm 1.0$ & $8,417 \pm 1,992$ & $44.2 \pm 2.4$ & $41.7 \pm 3.1$ & $53.7 \pm 3.8$ \\
\hline 24 & $74,020 \pm 6,696$ & $8.7 \pm 0.7$ & $7,973 \pm 1,486$ & $44.0 \pm 2.4$ & $42.3 \pm 1.8$ & $53.7 \pm 3.5$ \\
\hline 48 & $75,967 \pm 8,197$ & $9.2 \pm 1.3$ & $8,117 \pm 1,635$ & $43.7 \pm 2.3$ & $41.7 \pm 3.1$ & $53.6 \pm 3.9$ \\
\hline 168 & $76,353 \pm 6,688$ & $8.9 \pm 1.0$ & $8,379 \pm 1,896$ & $43.7 \pm 2.3$ & $41.4 \pm 2.1$ & $52.4 \pm 2.4$ \\
\hline \multicolumn{7}{|l|}{$\operatorname{rhTNF} \alpha$} \\
\hline-24 & $77,995 \pm 14,570$ & $7.6 \pm 1.4$ & $7,718 \pm 1,735$ & $47.4 \pm 3.9$ & $44.8 \pm 4.8$ & $58.0 \pm 3.8$ \\
\hline 0 & $84,230 \pm 16,800$ & $7.9 \pm 1.3$ & $7,800 \pm 1,931$ & $47.3 \pm 3.9$ & $44.5 \pm 5.1$ & $58.3 \pm 3.9$ \\
\hline 3 & $75,797 \pm 21,311$ & $6.6 \pm 1.6^{\ddagger}$ & $8,430 \pm 2,193$ & $47.9 \pm 3.5$ & $45.3 \pm 4.8$ & $57.2 \pm 4.4$ \\
\hline 6 & $67,281 \pm 17,841$ & $6.7 \pm 1.6^{\ddagger}$ & $7,586 \pm 902$ & $48.4 \pm 4.1$ & $44.9 \pm 4.2$ & $57.6 \pm 4.3$ \\
\hline 24 & $53,074 \pm 21,118^{* \neq}$ & $6.3 \pm 1.1^{* \ddagger}$ & $5,886 \pm 2,356^{* *}$ & $49.9 \pm 4.1^{* \pm}$ & $48.4 \pm 4.6^{* \neq}$ & $59.2 \pm 4.8^{\ddagger}$ \\
\hline 48 & $64,351 \pm 14,430$ & $6.5 \pm 0.8^{\ddagger}$ & $6,619 \pm 2,321$ & $49.7 \pm 4.6^{* \pm}$ & $47.5 \pm 6.1$ & $59.8 \pm 4.8^{\ddagger}$ \\
\hline 168 & $85,863 \pm 21,386$ & $7.7 \pm 1.6$ & $8,877 \pm 2,928$ & $47.7 \pm 6.2$ & $45.1 \pm 8.2$ & $57.6 \pm 6.4$ \\
\hline
\end{tabular}

${ }^{*} P<0.05$ as compared to baseline. ${ }^{\ddagger} P<0.05$ as compared to control group. 


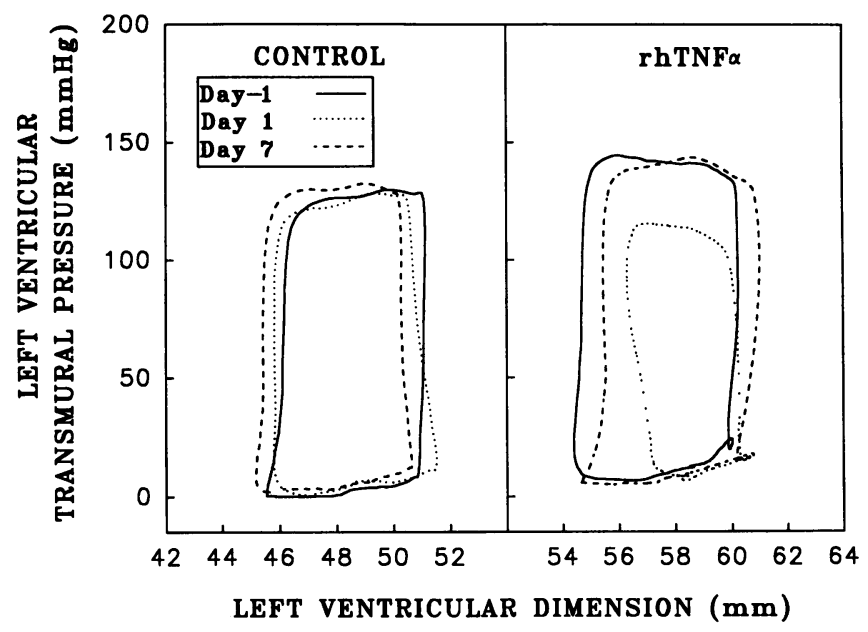

Figure 2. Transmural pressure-minor axis dimension loops for individual cardiac cycles. $1 \mathrm{~d}$ after the infusion of $\operatorname{rhTNF} \alpha$, ejection shortening and peak-systolic $P_{\mathrm{TM}}$ were reduced despite preservation of preload (end-diastolic dimension). By $7 \mathrm{~d}$, ejection shortening and peak-systolic pressure were restored.

ministration of heat-inactivated or active $\operatorname{rhTNF} \alpha$, there were no significant changes in subepicardial or subendocardial blood flow.

6-keto-PGF $F_{1 \alpha}($ Table VI). There were no significant differences between the two groups in baseline venous plasma levels of 6-keto-PGF ${ }_{1 \alpha}$. Administration of active rhTNF $\alpha$ elicited significant increases in 6-keto- $\mathrm{PGF}_{1 \alpha}$ at 3 and $6 \mathrm{~h}$. By $24 \mathrm{~h}$, plasma levels of 6-keto-PGF ${ }_{1 \alpha}$ returned to baseline.

\section{Discussion}

Effect of $r h T N F \alpha$ on LV function. Infusion of rhTNF $\alpha$ resulted in reversible systolic and diastolic LV dysfunction in chronically instrumented, conscious dogs. The onset of myocardial dysfunction was not observed until $24 \mathrm{~h}$ after the infusion of $\operatorname{rhTNF} \alpha$. At this time, HR was significantly increased, and

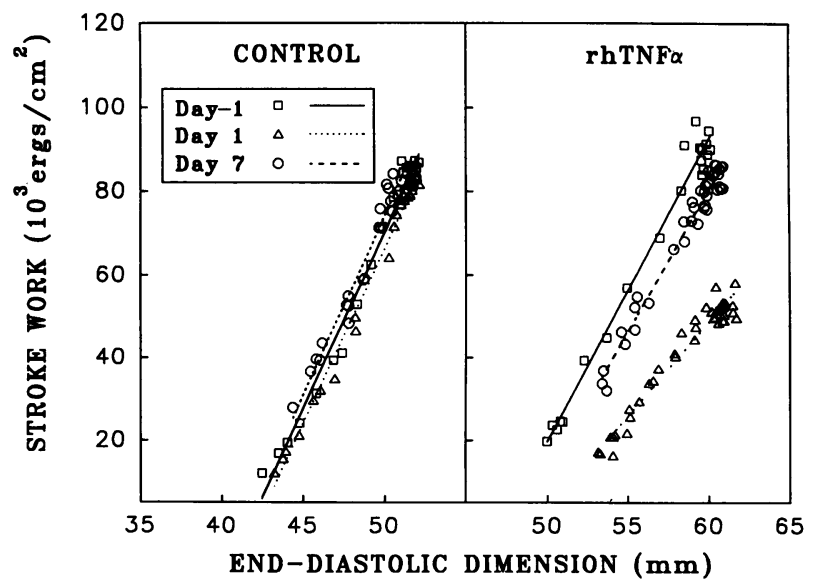

Figure 3. LV end-diastolic dimension-stroke work relationships in representative animals. $1 \mathrm{~d}$ after infusion of active rhTNF $\alpha$, the end-diastolic dimension-stroke work relationship was shifted to the right with a small decrease in slope. The position and slope of this relationship were nearly restored at $7 \mathrm{~d}$.

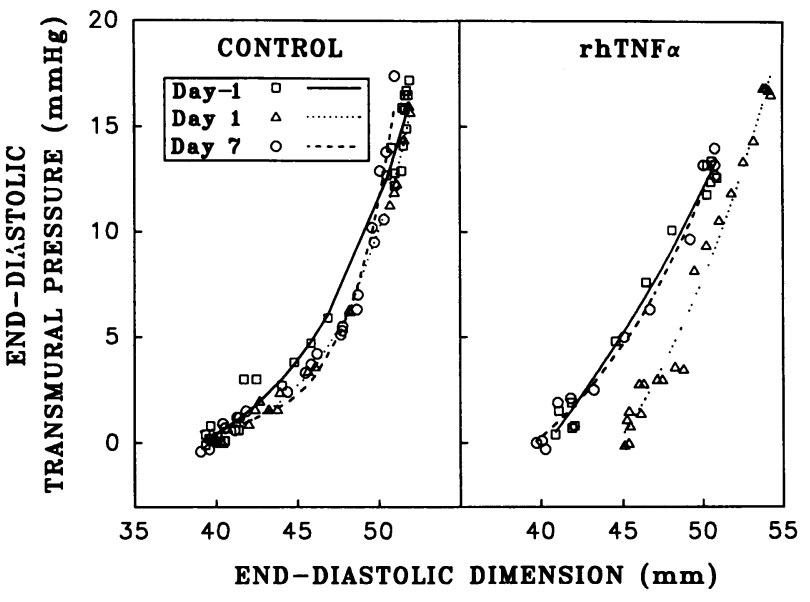

Figure 4. End-diastolic relationships between $P_{\mathrm{TM}}$ and LV dimension in representative animals, $1 \mathrm{~d}$ after active infusion of rhTNF $\alpha$ the $P_{\mathrm{TM}}$-dimension relationship was displaced to the right, with larger dimension at any given $P_{\mathrm{TM}}$, including $P_{\mathrm{TM}}=0 \mathrm{mmHg}$. The position of this relationship was restored at $7 \mathrm{~d}$.

peak systolic $P_{\mathrm{TM}}, \bar{P}_{\mathrm{A}}$, and SVRI were significantly decreased. LV end-diastolic $P_{\mathrm{TM}}$ ( preload) was maintained at baseline levels by infusing large volumes of normal saline. Despite the presence of myocardial dysfunction and decreased stroke volume, $\dot{Q}$ was well maintained. By $72 \mathrm{~h}, \mathrm{LV}$ function recovered to baseline in all animals.

A hyperdynamic circulatory state with concomitant depression of myocardial function similar to that observed in this study has been described in studies of sepsis and septic shock $(24,26-31)$. Thus, our data suggest that rhTNF $\alpha$ is capable of eliciting the pattern of hemodynamic derangements and myocardial dysfunction characteristic of the sepsis syndrome. Our findings are therefore consistent with the hypothesis that TNF $\alpha$ is a mediator of some of the circulatory and cardiac manifestations of sepsis and septic shock. In the present study, systolic myocardial dysfunction was evidenced by a rightward shift and

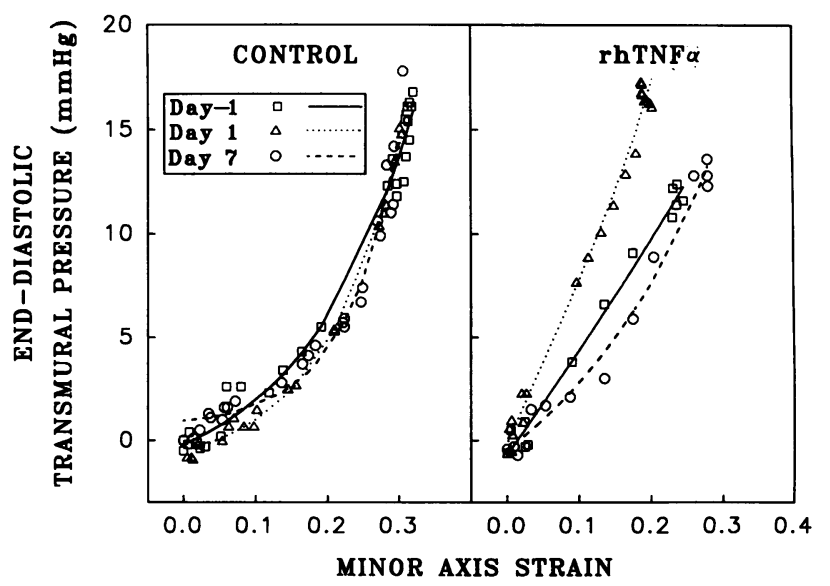

Figure 5. End-diastolic relationships between $P_{\mathrm{TM}}$ and normalized LV dimension (strain) in representative animals. $1 \mathrm{~d}$ after the infusion of active rhTNF $\alpha$, the $P_{\mathrm{TM}}$-strain relationship was displaced to the left with higher $P_{\mathrm{TM}}$ at any given strain. By $7 \mathrm{~d}$, the $P_{\mathrm{TM}}-$ strain relationship had returned close to its baseline position. 


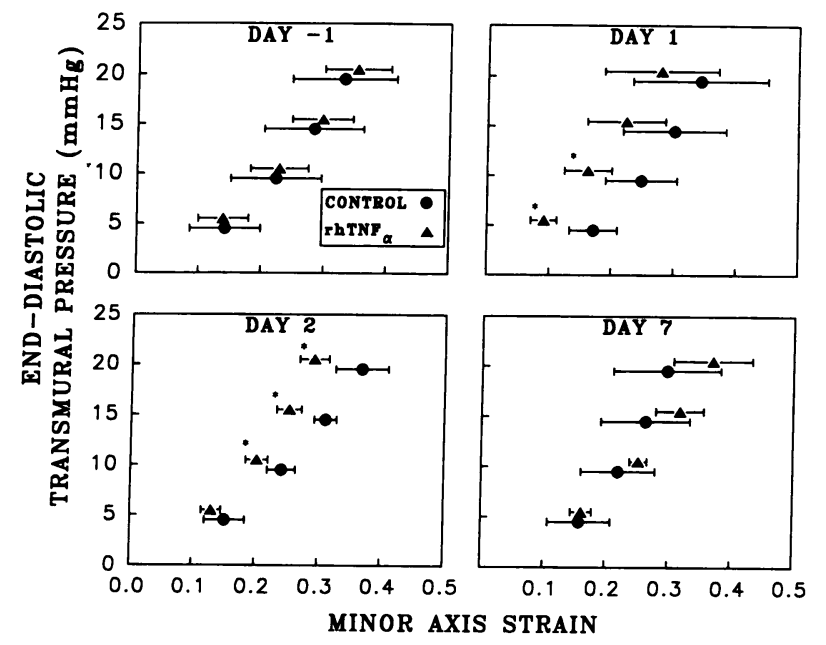

Figure 6. Means of end-diastolic $P_{\mathrm{TM}}$-strain data for the two groups of dogs. The $P_{\mathrm{TM}}$-strain relationship of the group that received active rhTNF $\alpha$ was displaced to the left of the $P_{\mathrm{TM}}$-strain relationship of the control animals on day 1 , with significantly smaller strains at 5 and $10 \mathrm{mmHg}$ of pressure. On day 2, strains in the active rhTNF $\alpha$ group were significantly smaller than strains in the control group at 10,15 , and $20 \mathrm{mmHg}$.

depression of the slope of the preload recruitable stroke work relationship, so that at any given LV preload (end-diastolic dimension), there was a significant reduction in the analogue of LV stroke work. The reduction in stroke work was due to both a decrease in fractional shortening of the minor axis dimension during the ejection phase of systole, and a decrease in peak systolic LV pressure. Myocardial depression was sufficient to decrease ejection shortening despite a concomitant reduction in SVRI (a proxy for LV afterload) and maintenance of baseline levels of preload (end-diastolic $P_{\mathrm{TM}}$ and EDL). Fractional ejection shortening was depressed at 3 and $6 \mathrm{~h}$, possibly owing to either increases in afterload, decreases in preload, or decreases in contractility that were not detectable in our model. Systolic myocardial dysfunction at $24 \mathrm{~h}$ also was evidenced by a significant reduction in the maximal rate of rise of $\mathrm{LV}$ pressure during isovolumic systole $(\mathrm{d} P / \mathrm{d} t)$. This parameter is sensitive to loading conditions, however, and may have been influenced by the decrease in peak systolic $P_{\mathrm{TM}}$.

The most important finding of this study was the observation that infusion of rhTNF $\alpha$ caused significant diastolic dysfunction of the left ventricle characterized by these features: $(a)$

Table V. Effects of rhTNF $\alpha$ on Myocardial Blood Flow

\begin{tabular}{ccc}
\hline Time & Subendocardial flow & Subepicardial flow \\
\hline$h$ & \multicolumn{3}{c}{$\mathrm{ml} \cdot \mathrm{min}^{-1} \cdot \mathrm{g}^{-1}$} \\
Control & & \\
0 & $1.14 \pm 0.20$ & $0.96 \pm 0.08$ \\
48 & $1.07 \pm 0.32$ & $0.93 \pm 0.30$ \\
168 & $1.10 \pm 0.54$ & $0.94 \pm 0.50$ \\
rhTNF $\alpha$ & & \\
0 & $1.09 \pm 0.81$ & $0.83 \pm 0.44$ \\
48 & $0.94 \pm 0.31$ & $0.72 \pm 0.15$ \\
168 & $0.89 \pm 0.61$ & $0.75 \pm 0.41$
\end{tabular}

Table VI. Effects of rhTNF $\alpha$ on Plasma Levels of 6-keto-PGF $F_{1 \alpha}$

\begin{tabular}{cc}
\hline Time & 6-keto-PGF Ia \\
\hline$h$ & $p g / m l$ \\
Control & \\
-24 & $97 \pm 167$ \\
0 & $113 \pm 191$ \\
3 & $102 \pm 183$ \\
6 & $71 \pm 129$ \\
24 & $71 \pm 118$ \\
48 & $81 \pm 135$ \\
168 & $86 \pm 173$ \\
rhTNF $\alpha$ & \\
-24 & $57 \pm 68$ \\
0 & $31 \pm 57$ \\
3 & $548 \pm 299^{* \pm}$ \\
6 & $1,110 \pm 258^{* \ddagger}$ \\
24 & $84 \pm 101$ \\
48 & $70 \pm 107$ \\
168 & $53 \pm 81$
\end{tabular}

${ }^{*} P<0.05$ as compared to baseline. ${ }^{\ddagger} P<0.05$ as compared to control group.

a significant increase in $\mathrm{LV}$ unstressed dimension, $L_{0}$, (i.e., diastolic creep); (b) a rightward shift of the LV end-diastolic $P_{\mathrm{TM}}$-dimension relationship generated during vena caval occlusions; and (c) a leftward shift of the $\mathrm{LV}$ end-diastolic $P_{\mathrm{TM}^{-}}$ strain relationship. Recent experimental studies have demonstrated LV dilatation $48 \mathrm{~h}$ after administration of rhTNF $\alpha$ (19). Whether this change represents physiologic LV dilatation or a change in LV chamber compliance was investigated in our model by analyzing changes in unstressed dimension and strain (fractional extension from unstressed dimension). 24 and $48 \mathrm{~h}$ after the infusion of $\operatorname{rhTNF} \alpha$, there was an increase in unstressed dimension (creep) and a significant leftward shift of the LV end-diastolic $P_{\mathrm{TM}}$-strain relationship, so that at any given end-diastolic strain, there was a greater LV end-diastolic $P_{\text {TM }}$. The findings suggest that the administration of rhTNF $\alpha$ alters the diastolic elastic properties of the $\mathrm{LV}$ wall, resulting in a significant reduction in LV chamber compliance. Chamber compliance can also be altered by changes in external constraints to filling (pressure and volume loading of the right ventricle or increases in intrapericardial pressure [45]), however, there was no evidence for these mechanisms in the present study. Specifically, right atrial filling pressures were not significantly different over time or between control or rhTNF $\alpha$ groups (data not shown). The finding that diastolic function is impaired, suggests that the LV dilatation noted by us and by Natanson et al. (19) is not simply dilatation of the left ventricle along its normal pressure-volume relationship to compensate for systolic dysfunction.

Stahl and colleagues ( 31 ) demonstrated diastolic creep with decreased LV diastolic compliance during sepsis induced by cecal ligation and puncture in dogs. Because the changes in diastolic LV function elicited by $\operatorname{rhTNF} \alpha$ are similar to those observed in this canine model of sepsis, it is plausible to hypothesize that TNF $\alpha$ is a mediator of sepsis-induced alterations in the diastolic mechanical properties of the myocardium. 
During the course of several days, there are three mechanisms that could explain the rhTNF $\alpha$-induced elongation of the external diameter of the left ventricle at zero stress: $(a)$ elongation of myocardial fibers, $(b)$ rearrangement of the interstitial matrix, and $(c)$ formation of myocardial edema. Studies examining cardiac enlargement during models of ischemic injury and hemodynamic overload have demonstrated that increases in ventricular dimension can in part be accounted for by changes in fiber length (reflected by changes in sarcomere length [46-48]), by slippage and realignment of the fibers (orderly rearrangement of the interstitial matrix $[48,49])$, and by disruption of the interstitial matrix $(48,50)$. Although elongation of sarcomere length and slippage between fiber layers probably occurs during ventricular expansion related to physiologic increases in preload, the elongation of dimension at a fixed stress (zero) suggests a change in fiber length or fiber arrangement that is not immediately reversible by physiologic restoring forces. In the case of $\operatorname{rhTNF} \alpha$-induced diastolic dysfunction, it is unknown whether elongation of unstressed dimension represents injury to the myocardial fibers and contractile proteins or disruption of the interstitial matrix. In the setting of reversible contractile dysfunction associated with myocardial stunning, extensive damage to the interstitial matrix has been demonstrated (50). The interstitial injury accompanying myocardial stunning is detectable within 3-4 h, and occurs in the absence of a local inflammatory response or myocardial necrosis. Invoking damage to the interstitial matrix as the cause of the ventricular enlargement observed in the present study would be compatible with the reversibility of the creep induced by $\operatorname{rhTNF} \alpha$, but would not in itself explain the delayed onset of creep.

The measurement of an external LV diameter with epicardial dimension transducers includes the measurement of two wall thicknesses. If infusion of rhTNF $\alpha$ elicited the formation of myocardial edema with a concomitant increase in wall thickness, an increase in the external anterior-posterior minor axis dimension could have occurred in our experiments without a true increase in the internal diameter and volume of the left ventricle. We did not measure water content of the myocardium or changes in wall thickness to exclude this possibility. However, the large mass of edema necessary to account for the observed change in $L_{0}$ would likely have caused far more severe systolic dysfunction. For an extension of $L_{0}$ from 4.5 to $4.8 \mathrm{~cm}$ to occur on the basis of an increase in wall thickness only, enough edema would have to be present in an equatorial LV ring to increase its mass by $\sim 20 \%$. Previous studies have demonstrated that, with a comparable increase in LV mass owing to edema, cardiac output is reduced $\sim 50 \%$ at fixed preload (left atrial pressure $=15 \mathrm{mmHg})(51)$.

Whether TNF $\alpha$-induced myocardial injury is primarily to myocytes or to the interstitial matrix, the intermediate mechanisms underlying this injury remain unknown. Both direct effects of TNF $\alpha$ on the myocardium or effects by secondary mediators seem plausible. It is unlikely that myocardial depression in our study was the result of rhTNF $\alpha$-induced systemic metabolic abnormalities. At the time of maximum myocardial depression $(24 \mathrm{~h})$, animals were only mildly acidemic $(\mathrm{pH}$ $7.31 \pm 0.03$ ). It is unlikely that this level of acidosis can account for the observed degree of systolic dysfunction myocardial depression, since at $6 \mathrm{~h}$, when systemic acidosis was more severe, there was no evidence of myocardial depression. Ventricular dysfunction also cannot be attributed to changes in subendocar- dial or subepicardial blood flow. Both systolic and diastolic dysfunction were evident at $48 \mathrm{~h}$, when $\dot{Q}_{M}$ was not significantly less than baseline.

Myocardial injury induced by TNF $\alpha$ may depend upon the recruitment and activation of neutrophils. This hypothesis is consistent with these findings: (a) TNF $\alpha$ enhances margination and infiltration of neutrophils through endothelium (52, $53)$; (b) TNF $\alpha$ promotes adhesion of neutrophils to cardiac myocytes (54); and (c) neutrophils participate in ischemic myocardial injuries that result in both cell death and reversible contractile dysfunction (55-60). There is also evidence that TNF $\alpha$ promotes systemic and local release of secondary mediators from white blood cells (61-65) that could potentially compromise myocardial contractile function (66-70). The finding in this study that the onset of ventricular dysfunction occurs 6-24 h after administration of rhTNF $\alpha$, could be explained by neutrophil activation and subsequent infiltration into the myocardium with systemic and local release of mediators over a period of several hours.

Recent in vitro studies have described a direct effect of TNF $\alpha$ on the sympathomimetic stimulation of myocardial contractile function. Myocytes exposed to TNF $\alpha$ for $72 \mathrm{~h} \mathrm{dem}$ onstrate a decrease in isoproterenol-stimulated augmentation of contractile activity and production of cAMP (34). These effects occur without a change in the density or affinity of $\beta$ adrenergic receptors. The response to forskolin, an inhibitor of adenylate cyclase, is not affected by exposure to TNF $\alpha$ (34). These data suggest that myocardial cells express receptors for TNF $\alpha$, which when activated, elicit derangements in the $\beta$ receptor-regulatory GTP binding protein-adenylate cyclase transduction system (71).

Effects of rhTNF $\alpha$ on hemodynamics, prostacyclin release, and arterial oxygenation. Consistent with previous reports by others (22), we observed a marked increase in circulating levels of 6-keto-PGF ${ }_{1 \alpha}$ after infusion of $\operatorname{rhTNF} \alpha$. We measured levels of this prostanoid as an internal check to document that the cytokine was indeed active. Also consistent with previously published results $(21,22)$ was our observation that infusion of rhTNF $\alpha$ elicited fever and arterial hypoxemia, and decreased SVRI during the early (3-24 h) period after infusion.

Critique of experimental methods. The assessment of systolic and diastolic myocardial function in this study relied upon the analysis of a single external ventricular dimension (anterior-posterior axis diameter). Changes in this linear dimension have been substituted for changes in LV volume. Systolic stroke work is a pressure-volume integral rather than a pressure-dimension integral, and a more complete description of LV chamber compliance requires analysis of the diastolic pressure-volume relationship, rather than a pressure-diameter relationship. However, Rankin et al. (72) have demonstrated in a similar experimental preparation that changes in the anterior-posterior minor axis dimension during the cardiac cycle are highly correlated with changes in LV volume. We have validated under baseline conditions that changes in minor axis dimension during the ejection phase are highly correlated with changes in stroke volume, measured independently with the pulmonary artery flow probe used in this study (F. D. Pagani, unpublished observations).

The present study leaves some uncertainty in the time of onset of mechanical dysfunction of the left ventricle. Because no data were collected between $6 \mathrm{~h}$ and $24 \mathrm{~h}$, the true onset of LV dysfunction may have occurred between these two time 
points. Latent $L V$ contractile dysfunction at earlier time points may have been masked by adrenergic stimulation. Furthermore, the statistical power of this study was limited by the availability of only a seven- animal $\times$ five-animal matrix of data for final analysis.

Finally, rather than obtaining tissue from ventricles for histologic and biochemical analysis at the time of their maximal dysfunction (24-48 h), we elected to document the reversibility of ventricular dysfunction and the time course of recovery. Future studies in which tissue is harvested 24-48 $\mathrm{h}$ after the administration of rhTNF $\alpha$ will therefore be necessary to elucidate the histologic and biochemical substrates of the myocardial injury.

\section{Acknowledgments}

We thank Ms. Kari Lodico for technical assistance and Ms. Penny Bentley, Ms. Carol Panek, and Ms. Claire Cronin for their assistance preparing the manuscript.

This work was supported in part by grants from the National Institutes of Health (R29 GM37631 to M. P. Fink; R29 HL46280-01 to M. S. Visner) and a postdoctoral fellowship from the Massachusetts Affiliate of the American Heart Association (F. D. Pagani).

\section{References}

1. Waage, A., T. Espevik, and J. Lamvik. 1986. Detection of tumour necrosis factor-like cytotoxicity in serum from patients with septicaemia but not from untreated cancer patients. Scand. J. Immunol. 24:739-743.

2. Waage, A., T. Espevik, and A. Halstensen. 1987. Association between tumour necrosis factor in serum and fatal outcome in patients with meningococcal disease. Lancet. $i: 355-357$.

3. Michie, H. R., K. R. Manogue, D. R. Spriggs, A. Revhaug S. O'Dwyer, C. A. Dinarello, A. Cerami, S. M. Wolff, and D. G. Wilmore. 1988. Detection of circulating tumor necrosis factor after endotoxin administration. N. Engl.J. Med. 318:1481-1486.

4. Mathison, J. C., E. Wolfson, and R. J. Ulevitch. 1988. Participation of tumor necrosis factor in the mediation of gram negative bacterial lipopolysaccharide-induced injury in rabbits. J. Clin. Invest. 81:1925-1937.

5. Evans, G. F., Y. M. Snyder, L. D. Butler, and S. H. Zuckerman. 1989. Differential expression of interleukin-1 and tumor necrosis factor in murine septic shock models. Circ. Shock. 29:279-290.

6. Hesse, D. G., K. J. Tracey, Y. Fong, K. R. Manogue, M. A. Palladino, Jr., A. Cerami, and G. T. Shires. 1988. Cytokine appearance in human endotoxemia and primate bacteremia. Surg. Gynecol. Obstet. 166:147-153.

7. Kiener, P. A., F. Marek, G. Rodgers, L. Pin-Fang, G. Warr, G., and J. Desiderio. 1988. Induction of tumor necrosis factor, IFN-gamma, and acute lethality in mice by toxic and non-toxic forms of lipid A. J. Immunol. 141:870874.

8. Blick, M., S. A. Sherwin, M. Rosenblum, and J. Gutterman. 1987. Phase I study of recombinant tumor necrosis factor in cancer patients. Cancer. Res. 47:2986-2989.

9. Spriggs, D. R., M. L. Sherman, H. Michie, K. A. Arthur, K. Imamura, D. Wilmore, E. Frei III., and W. K. Kufe. 1988. Recombinant human tumor necrosis factor administered as a 24-hour intravenous infusion: a phase I and pharmacologic study. J. Natl. Cancer. Inst. 80:1039-1044.

10. Remick, D. G., R. G. Kunkel, J. W. Larrick, and S. L. Kunkel. 1987. Acute in vivo effects of human recombinant tumor necrosis factor. Lab. Invest. 56:583-590.

11. Rothstein, J. L., and H. Schreiber. 1988. Synergy between tumor necrosis factor and bacterial products causes hemorrhagic necrosis and lethal shock in normal mice. Proc. Natl. Acad. Sci. USA. 85:607-611.

12. Gaskill, H. V. 1988. Continuous infusion of tumor necrosis factor: mechanisms of toxicity in the rat. J. Surg. Res. 44:664-671.

13. Kettlehut, I. C., W. Fiers, and A. L. Goldberg. 1987. The toxic effects of tumor necrosis factor in vivo and their prevention by cyclooxygenase inhibitors. Proc. Natl. Acad. Sci. USA. 84:4273-4277.

14. Tracey, K. J., B. Beutler, S. F. Lowry, J. Merryweather, S. Wolpe, I. W. Milsark, R. J. Hariri, T. J. Fahey, A. Zentella, J. D. Albert, et al. 1986. Shock and tissue injury induced by recombinant human cachectin. Science (Wash. DC). 234:470-474.

15. Schirmer, W. J., J. M. Schirmer, and D. E. Fry. 1989. Recombinant human tumor necrosis factor produces hemodynamic changes characteristic of sepsis and endotoxemia. Arch. Surg. 124:445-448.15.

16. Turner, C. R., K. M. Esser, E. B. Wheeldon, Slivjak, and E. F. Smith. 1989. Cardiovascular and pulmonary effects of human recombinant tumor necrosis factor in the conscious rat. Circ. Shock. 28:369-384.

17. Okusawa, S., J. A. Gelfand, T. Ikejima, R. J. Connolly, and C. A. Dinarello. 1988. Interleukin 1 induces a shock-like state in rabbits. J. Clin. Invest. 81:1162-1172.

18. Evans, D. A., D. O. Jacobs, A. Revhaug, and D. W. Wilmore. 1989. The effects of tumor necrosis factor and their selective inhibition by ibuprofen. Ann. Surg. 209:312-321.

19. Natanson, C., P. W. Eichenholz, R. L. Danner, P. Q. Eichacker, W. D. Hoffman, G. C. Kuo, S. M. Banks, T. J. MacVittie, and J. E. Parrillo. 1989. Endotoxin and tumor necrosis factor challenges in dogs simulate the cardiovascular profile of human septic shock. J. Exp. Med. 169:823-832.

20. Tracey, K. J., S. F. Lowry, T. J. Fahey III, J. D. Albert, Y. Fong, D. Hesse, B. Bentler, K. R. Manaque, S. Calvano, H. Wei, et al. 1987. Cachectin/tumor necrosis factor induces lethal shock and stress hormone responses in the dog. Surg. Gynecol. Obstet. 164:415-422.

21. Johnson, J., B. Meyrick, G. Jesmok, and K. L. Brigham. 1989. Human recombinant tumor necrosis factor alpha infusion mimics endotoxemia in awake sheep. J. Appl. Physiol. 66:1448-1454.

22. Kreil, E. A., E. Greene, C. Fitzgibbon, D. R. Robinson, and W. M. Zapol. 1989. Effects of recombinant human tumor necrosis factor alpha, lymphotoxin and $E$. coli lipopolysaccharide on hemodynamics, lung microvascular permeability, and eicosanoid synthesis in anesthetized sheep. Circ. Res. 65:502-514.

23. Tracey, K. J., Y. Fong, D. G. Hesse, K. R. Manogue, A. T. Lee, G. C. Kuo, S. F. Lowry, and A. C. Cerami. 1987. Anti-cachectin/TNF monoclonal antibodies prevent septic shock during lethal bacteraemia. Nature (Lond.). 330:662-664.

24. Beutler, B., I. W. Milsark, and A. C. Cerami. 1985. Passive immunization against cachectin/tumor necrosis factor protects mice from lethal effect of endotoxin. Science (Wash. DC). 229:869-871.

25. Ellrodt, A. G., M. S. Riedinger, A. Kimchi, D. S. Berman, J. Maddahi, H. J. C. Swan, and G. H. Murata. 1985. Left ventricular performance in septic shock: reversible segmental and global abnormalities. Am. Heart J. 110:402-408.

26. MacLean, L. D., W. G. Mulligan, A. P. H. McLean, and J. H. Duff. 1967. Patterns of septic shock in man: a detailed study of 56 patients. Ann. Surg. 166:543-562.

27. Natanson, C., R. L. Danner, R. R. Elin, J. M. Hosseini, K. W. Peart, S. M Banks, T. J. MacVittie, R. I. Walker, and J. E. Parrillo. 1989. Role of endotoxemia in cardiovascular dysfunction and mortality. J. Clin. Invest. 83:243-251.

28. Parker, M. M., J. H. Shelhamer, S. L. Bacharach, M. V. Green, C. Natanson, T. M. Frederick, B. A. Damske, and J. E. Parrillo. 1984. Profound but reversible myocardial depression in patients with septic shock. Ann. Intern. Med. 100:483-490.

29. Natanson, C., R. L. Danner, M. P. Fink, T. J. MacVittie, R. I. Walker, J. J. Conklin, and J. E. Parrillo. 1988. Cardiovascular performance with E. coli challenges in a canine model of human sepsis. Am. J. Physiol. 254:H558-H569.

30. Natanson, C., M. P. Fink, H. K. Ballantyne, H. K., T. J. MacVittie, J. J. Conklin, and J. E. Parrillo. 1986. Gram-negative bacteremia produces both severe systolic and diastolic cardiac dysfunction in a canine model that stimulates human septic shock. J. Clin. Invest. 78:259-270.

31. Stahl, T. J., P. B. Alden, W. S. Ring, R. C. Madoff, and F. B. Cerra. 1990. Sepsis-induced diastolic dysfunction in chronic canine peritonitis. Am. J. Physiol. 258:H625-H633.

32. Pasque, M. K., P. Van Trigt, G. L. Pellom, B. M. Freedman, and A. S. Wechsler. 1988. Assessment of the intrinsic contractile status of the heart during sepsis by myocardial pressure-dimension analysis. Ann. Surg. 208:110-117.

33. Reference removed in proof

34. Gulick, T., M. K. Chung, S. J. Pieper, L. G. Lange, and G. F. Schreiner. 1989. Interleukin- 1 and tumor necrosis factor inhibit cardiac myocyte $\beta$-adrenergic responsiveness. Proc. Natl. Acad. Sci. USA. 86:6753-6757.

35. Glower, D. D., J. A. Spratt, N. D. Snow, J. S. Kabas, J. W. Davis, C. O. Olsen, G. S. Tyson, D. C. Sabiston, and J. S. Rankin. 1985. Linearity of the Frank-Starling relationship in intact heart: the concept of preload recruitable stroke work. Circulation. 71:994-1009.

36. Pagani, F. D., L. S. Baker, M. A. Knox, H. Cheng, M. P. Fink, and M. S. Visner. 1990. Tumor necrosis factor alpha causes diastolic creep and reversible left ventricular systolic dysfunction in conscious dogs. Surg. Forum. 41:40-42. (Abstr.)

37. Fink, M. P., W. M. Gardiner, R. Roethel, and J. R. Fletcher. 1985. Plasma levels of 6-keto-PGF $F_{1 \alpha}$ but not $\mathrm{TxB}_{2}$ increase in rats with peritonitis due to cecal ligation. Circ. Shock. 16:297-305.

38. Hale, S. L., K. J. Alker, and R. A. Kloner. 1988. Evaluation of nonradioactive, colored microspheres for measurement of regional myocardial blood flow in dogs. Circulation. 78:428-434.

39. Glower, D. D., J. A. Spratt, J. S. Kabas, J. W. Davis, and J. S. Rankin 1988. Quantification of regional myocardial dysfunction after acute ischemic injury. Am. J. Physiol. 255:H85-H93. 
40. Abel, F. L. 1981. Maximum negative dP/dt as an indicator of end systole. Am. J. Physiol. 240:H676-H682.

41. Rankin, J. S., C. E. Arentzen, P. A. McHale, D. Ling, and R. W. Anderson. 1974. Viscoelastic properties of the diastolic left ventricle in the conscious dog. Circ. Res. 41:37-45.

42. Dunn, O. J., and V. A. Clark. 1987. Applied Statistics: Analysis of Variance and Regression. John Wiley \& Sons, Inc., New York. 236 pp.

43. Box, G. E. P., W. G. Hunter, and J. S. Hunter. 1978. Statistics for Experiments, An Introduction to Design, Data Analysis and Model Building. John Wiley \& Sons, Inc., New York. 204 pp.

44. Milliken, G. A., and D. E. Johnson. 1984. Analysis of Messy Data. Lifetime Learning Publications, Belmont, CA. 33 pp.

45. Glantz, S. A., and W. W. Parmley. 1978. Factors which affect the diastolic pressure-volume curve. Circ. Res. 42:171-180.

46. Zhao, M., R. Forman, E. H. Sonnenblick. 1989. Pressure-sarcomere length relationship in the stunned myocardium. Circulation. 80:II-97.

47. Glower, D. D., J. Schaper, J. S. Kabas, H. M. Hoffmeister, W. Schaper, J. A. Spratt, J. W. Davis, and J. S. Rankin. 1987. Relation between reversal of diastolic creep and recovery of systolic function after ischemic myocardial injury in conscious dogs. Circ. Res. 60:850-860.

48. Factor, S. M., M. Flomenbaum, M. Zhao, C. Eng, and T. F. Robinson. 1988. The effects of acutely increased ventricular cavity pressure on intrinsic myocardial connective tissue. J. Am. Coll. Cardiol. 1582-1589.

49. Weisman, H. F., D. E. Bush, J. A. Mannisi, M. L. Weisfeldt, and B. Healy. 1988. Cellular mechanisms of myocardial infarct expansion. Circulation. 78:186-201.

50. Zhao, M., H. Zhang, T. F. Robinson, S. M. Factor, and E. H. Sonnenblick. 1987. Profound Structural alterations of the extracellular collagen matrix in postischemic dysfunctional ("stunned") but viable myocardium. J. Am. Coll. Cardiol. 6:1322-1334.

51. Laine, G. A., and S. J. Allen. 1991. Left ventricular myocardium edema. Lymph flow, interstitial fibrosis, and cardiac function. Circ. Res. 68:1713-1721.

52. Pohlman, T. H., K. A. Stanness, P. G. Beatty, H. D. Ochs, and J. M. Harlan. 1986. An endothelial cell surface factor(s) induced in vitro by lipopolysaccharide, interleukin 1 , and tumor necrosis factor- $\alpha$ increases neutrophil adherence by a CD18-dependent mechanism. J. Immunol. 136:4548-4553.

53. Moser, R., B. Schleiffenbaum, P. Groscurth, and J. Fehr. 1989. Interleukin-1 and tumor necrosis factor stimulate human vascular endothelial cells to promote transendothelial neutrophil passage. J. Clin. Invest. 83:444-445.

54. Entman, M. L., K. Youker, S. B. Shappell, C. Siegel, R. Rothiein, W. J. Dreyer, F. C. Schmalstieg, and C. W. Smith. 1990. Neutrophil adherence to isolated adult canine myocytes. J. Clin. Invest. 85:1497-1506.

55. Engler, R. L., G. W. Schmid-Schonbein, and R. S. Pavelec. 1983. Leukocyte capillary plugging in myocardial ischemia and reperfusion in the dog. Am.J. Pathol. 111:98-111.

56. Engler, R. L., M. D. Dahlgren, D. D. Morris, M. A. Peterson, and G. W Schmid-Schonbein. 1986. Role of leukocytes in response to acute myocardial ischemia and reflow in dogs. Am. J. Physiol. 251:H314-H322.

57. Engler, R., and J. W. Covell. 1987. Granulocytes cause reperfusion ventricular dysfunction after 15-minutes of ischemia in the dog. Circ. Res. 61:20-28.
58. Reynolds, J. M., and P. F. McDonagh. 1989. Early in reperfusion, leukocytes alter perfused coronary capillarity and vascular resistance. Am. J. Physiol. 256. 25:H982-H989.

59. Romson, J. L., B. G. Hook, S. L. Kunkel, G. D. Abrams, M. A. Schork, and B. R. Lucchesi. 1983. Reduction of the extent of ischemic myocardial injury by neutrophil depletion in the dog. Circulation. 67:1016-1023.

60. Simpson, P. J., R. F. Todd III., J. C. Fantone, J. K. Mickelson, J. D. Griffin, and B. R. Lucchesi. 1988. Reduction of experimental canine myocardial reperfusion injury by a monoclonal antibody (anti-Mol, anti-CD11b) that inhibits leukocyte adhesion. J. Clin. Invest. 81:624-629.

61. Bachwich, P. R., S. W. Chensue, J. W. Larrick, and S. L. Kunkel. 1986 Tumor necrosis factor stimulates interleukin 1 and prostaglandin $E_{2}$ production in resting macrophages. Biochem. Biophys. Res. Commun. 136:94-101.

62. Huber, M., B. Beutler, and D. Keppler. 1988. Tumor necrosis factor $\alpha$ stimulates leukotriene production in vivo. Eur. J. Immunol. 18:2085-2088.

63. Meyer, J. D., R. W. Yurt, R. Duhaney, D. G. Hesse, K. J. Tracey, Y. Fong, M. Verma, G. T. Shires, P. Dineen, S. F. Lowry, et al. 1988. Tumor necrosis factor-enhanced leukotriene $\mathrm{B}_{4}$ generation and chemotaxis in human neutrophils. Arch. Surg. 123:1454-1458.

64. Sun, X. M., and W. Hsueh. 1988. Bowel necrosis induced by tumor necrosis factor in rats is mediated by platelet activating factor. $J$. Clin. Invest. 81:1328-1331.60.

65. Tsujimoto, M., S. Yokota, J. Vilcek, and G. Weissmann. 1986. Tumor necrosis factor provokes superoxide anion generation from neutrophils. Biochem. Biophys. Res. Commun. 137:1094-1100.

66. Ezra, D., L. M. Boyd, G. Feuerstein, and R. E. Goldstein. 1983. Coronary constriction by leukotriene $\mathrm{C}_{4}, \mathrm{D}_{4}$, and $\mathrm{E}_{4}$ in the intact pig heart. Am. J. Cardiol. 51:1451-1454.

67. Mullane, K. M., and D. Fornabaio. 1988. Thromboxane synthetase inhibitors reduce infarct size by a platelet-dependent, aspirin-sensitive mechanism. Circ. Res. 62:668-678.

68. Mullane, K. M., M. A. Hatala, R. Kraemer, W. Sessa, and W. Westlin. 1987. Myocardial salvage induced by REV-5901, an inhibitor and antagonist of the leukotrienes. J. Cardiovasc. Pharmacol. 10:398-406.

69. Mullane, K. M., N. Read, J. A. Salmon, and S. Moncada. 1984. Role of leukocytes in acute myocardial infarction in anesthetized dogs: relationship to myocardial salvage by anti-inflammatory drugs. J. Pharmacol. Exp. Ther 288:510-522.

70. Przyklenk, K., and R. A. Kloner. 1986. Superoxide dismutase plus catalase improve contractile function in the canine model of "stunned myocardium." Circ. Res. 58:148-156.

71. Chung, M. K., T. Gulick, R. E. Rotondo, G. F. Schreiner, and L. G. Lange. 1990. Mechanisms of cytokine inhibition of B-adrenergic agonist stimulation of cyclic AMP in rat cardiac myocytes: Impairment of signal transduction. Circ. Res. 67:753-763.

72. Rankin, J. S., P. A. Mchale, C. E. Arentzen, D. Ling, J. C. Greenfield, and R. W. Anderson. 1976. The three-dimensional dynamic geometry of the left ventricle in the conscious dog. Circ. Res. 39:304-313. 